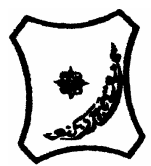

Bayero Journal of Pure and Applied Sciences, 8(2): 14 - 18

Received: June, 2015

Accepted: November, 2015

ISSN 2006 - 6996

\title{
HEALTH FACILITY-BASED SURVEY OF POLIOVIRUS ANTIBODY PREVALENCE AMONGST CHILDREN IN KEBBI STATE, NORTH WEST, NIGERIA.
}

\author{
${ }^{1}$ Yusuf, K.M., ${ }^{2}$ Jatau, E.D., ${ }^{2}$ Yakubu, S.E., ${ }^{2}$ Ahmad, ${ }^{3}$ B.S.Nuhu, A., ${ }^{2}$ Iya, Z.A. and ${ }^{4}$ Yahaya, A.E. \\ 1Department of Disease Control and Immunization, National Primary Health Care Development Agency Abuja, \\ Nigeria. \\ 2Department of Microbiology, Ahmadu Bello University Zaria, Nigeria. \\ 3Department of Disease Control and Immunization, National Primary Health Care Development Agency Abuja, \\ Nigeria. \\ 4Hassan Usman Katsina State Polytechnic \\ *Correspondence: ysfmawash@yahoo.co.uk, _+2348069569929
}

\section{ABSTRACT}

Background: High level of Poliovirus protective antibodies, must at all times be sustained in a community if poliomyelitis eradication is to be achieved. For some time now children have been vaccinated against poliomyelitis through various means in Northern Nigeria without authorities taking steps to evaluate the effectiveness of such activities. Aim: This research was focused on assessing the overall success of the Immunization programme using children whose mothers have access to immunization facilities. Materials and methods: A cross sectional survey was designed to enroll children whose mothers had access to Health Facilities across the state. Eighty blood samples of under - five years old children in Kebbi state were collected and tested for the presence of poliovirus antibodies. Indirect ELISA was used to detect for the presence of the antibodies. Results; Out of these samples collected, 65 (81.3\%) have antibodies to all the serotypes. While 75 (93.8\%), 71 (88.8\%) and 74 (92.5\%) have antibodies to poliovirus serotypes 1, 2 and 3 respectively. Older children 48 - 59 month had the highest poliovirus antibody prevalence 21 (95.5\%). Female children had higher prevalence than males. Children who have not received any vaccination against Poliovirus had lowest antibody prevalence $9(64.3 \%)$. Children who had more than four doses of the vaccine had the highest prevalence of Poliovirus antibodies. Urban children had higher Poliovirus antibody prevalence than their rural counterparts. Children whose fathers educational were up to tertiary level had higher antibody prevalence than those with either primary or secondary school level. Conclusion: This study found out that age of the children and educational level of the children fathers had a significant effect on the prevalence of antibodies at $P=0.05$. More work needs to be done in order to sustain the apparent success achieved in stopping the poliovirus circulation and outbreaks within the populace in Kebbi state Nigeria.

Keywords: Antibodies, Children, Kebbi State and Prevalence.

\section{INTRODUCTION}

Poliomyelitis is a highly infectious disease caused by a virus that mainly affects children under five years of age. There is no cure for the disease; it can only be prevented (Atkinson et al., 2007). Poliomyelitis is an acute viral infection which ranges in severity from a nonspecific illness to paralysis with permanent disability. Studies conducted revealed that individuals that have received adequate doses of oral polio vaccine, about 95\% develop immunity (Bodian et al., 1965).

A lot of factors come together to aid Poliovirus transmission as work done by Ohri et al., (1999) revealed. Doses of oral polio vaccine (OPV) taken, distance from the Health Facility offering Routine Immunization, age of the children sampled and other factors have been found to have either positive or negative effect on polio antibody prevalence by other researchers (Kew et al., 2005; Dashe et al., 2010). Neutralizing antisera has been used to classify polioviruses into their three distinct serotypes based on their pattern of reaction (Mary et al., 2010).

Programme decisions based on survey findings have been seen to contribute more towards improved and sustained quality of care in health facilities. Combined with periodic population-based outcome evaluations and mapping of public health data, health facility surveys are powerful instruments for improving service delivery. Health data provide basis for comparisons and can be used to identify needed interventional targets for programs as well as for program planning and evaluation. Primarily health surveys are supposed to help disseminate pertinent information regarding the burden of disease and risk factor trend within a particular community. Ensuring reliability, accuracy of data tools, representative samples, and the validity of participant responses, are some of the challenges faced by health surveys in general (Wilks et al., 2007)

In order to provide quality evidence for impact of immunization services in Kebbi State, we decided to conduct a Health Facility-based survey designed to track polio antibody prevalence in the state under different settings. Health Facility based survey was chosen as against community based survey primarily because of the ease of collecting and storing of the samples and secondarily for fear of possible refusal by parents to enrol their children. 


\section{MATERIALS AND METHODS STUDY AREA:}

Kebbi State is situated in North-Western Nigeria with its capital at Birnin Kebbi. It is bordered to the East by Sokoto state, to south by Niger and Zamfara states, and to the west by Benin and Niger republics. It has a total area of $36,800 \mathrm{~km}^{2}$. Agriculture is the main occupation of the people especially in rural areas. The state enjoys tropical continental type of climate, which is largely controlled by two air masses namely; tropical maritime and tropical continental blowing from Atlantic and Sahara desert respectively. The air masses determined the two dominant seasons, wet and dry. Humidity is $27 \%$ while wind blow at $11 \mathrm{Km} / \mathrm{h}$ in ESE direction. The State receive a mean annual rainfall of $800 \mathrm{~mm}$ between May to September with a peak period in August, the remaining period of the year is dry. The average temperature is $26^{\circ} \mathrm{C}$ and can rise up to $40^{\circ} \mathrm{C}$ in the peak of hot season (March-July). However, during harmattan, (December- February) temperature can falls to $21^{\circ} \mathrm{C}$. (Usman, 2013).

\section{Study design:}

The study was cross-sectional and was carried out from February - March 2014 involving 80 children drawn from different locations within the state. Children were conveniently included in the study if they lived in the state.

\section{Target group:}

Children ranging from 0 - 59 months of age were selected. Children were classified as having no dose at all, or having 1 or 2 or 3 or 4 and those with more than 4 OPV doses. As the father had the final say in the affairs of the household, his educational level was assessed.

\section{Questionnaire design and distribution:}

The study began after the ethical committee of the state gave approval for the study to be conducted. We took verbal and in some instances written consent from parents or caretakers before taking blood samples. A well structured but simple questionnaire was used to capture all the relevant information required.

\section{Collection of blood sample:}

Eighty blood samples were collected from the targeted age groups ( 0 - 59 months), after disinfecting the correct area of the arm with cotton soaked in Dettol. The blood samples were taken from male and females, urban and rural dwellers, and from children with differential parental educational levels.

About $5 \mathrm{ml}$ of blood sample was collected from each of the enrolled child, into a plain labelled tube, which was placed in ice packs laden vaccine carrier and carried to laboratory. Each tube with its contents was centrifuged at 3,000 revolutions per minute for 5 minutes. The serum was collected in another labelled tube and processed immediately or was stored in the freezer at -

$20^{\circ} \mathrm{C}$ until at a later time.

\section{ELISA analysis:}

The polio ELISA test kit manufactured by antibodiesonline $\mathrm{GmbH}$, was used for the detection of antibodies against specific polio virus serotype in the serum (Aliya et al., 2015).

\section{Statistical analysis:}

The statistical analyses were undertaken using Epi Info version 3.5.4. (Guevarra et al., 2014). A p value of less than 0.05 was considered statistically significant.

\section{RESULTS}

The age-group with the lowest poliovirus antibody prevalence is $0-11$ months, this is shown in Table 1 . The difference between the age-groups was statistically significant at $p<0.05$. The females had higher poliovirus antibody prevalence when compared with their male counterpart from the study population. This is shown in Table 1 below. However there was no significant difference between the two groups at $p<0.05$. 
Table 1. Distribution of children having antibodies to all the Poliovirus serotypes as per their agegroup and gender profiles in the State.

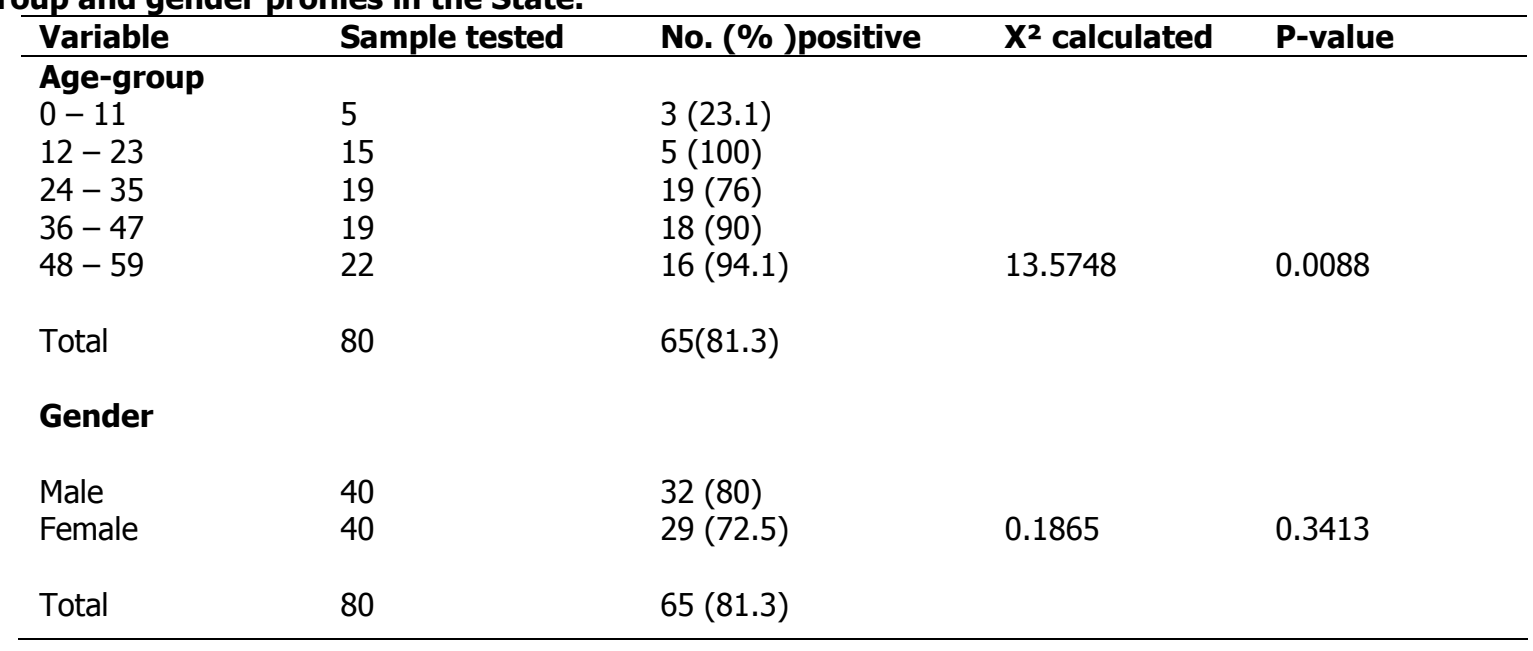

The proportion of children having antibodies to Poliovirus as a function of OPV vaccine taken is shown in table 2. There was no statistically significant difference between the various groups with different OPV dosages at $p<0.05$. Children whose parent's claimed to have taken 3 doses had the highest prevalence (100\%). The lowest prevalence of $64.3 \%$ was found amongst the children who had taken a single dose. Children in the urban area had higher polio antibody prevalence than children in the rural area as shown in table 2. However, the difference between the two places was not statistically significant at $\mathrm{P}<0.05$.

The prevalence of poliovirus antibodies as per father's educational level is shown in table 2 . Children whose father's educational level stopped at primary school level had the lowest polio antibody prevalence level. Whereas children, whose father's had education up to tertiary level, had the highest polio antibody prevalence, the difference between the groups was statistically $\begin{array}{llll}\text { significant } \quad \text { at } & P & <0.05 \text {. }\end{array}$

Table 2. Proportion of children having antibodies to all the Poliovirus serotypes in the state as per the number of OPV doses received, child's location and father's educational level.

\begin{tabular}{|c|c|c|c|c|}
\hline Variable & Sample tested & No.(\%) positive & $\mathrm{X}^{2}$ calculated & P-value \\
\hline \multicolumn{5}{|c|}{ OPV doses } \\
\hline 0 & 8 & $6(75)$ & & \\
\hline 1 & 14 & $9(64.3)$ & & \\
\hline 2 & 14 & $10(71.4)$ & & \\
\hline 3 & 8 & $8(100)$ & & \\
\hline 4 & 14 & $12(85.7)$ & & \\
\hline$>4$ & 22 & $20(90.9)$ & 7.1129 & 11.0705 \\
\hline Total & 80 & $65(81.3)$ & & \\
\hline \multicolumn{5}{|l|}{ Location } \\
\hline Urban & 54 & $47(87)$ & & \\
\hline Rural & 26 & $18(69.2)$ & 3.6526 & 0.0359 \\
\hline Total & 80 & $65(81.3)$ & & \\
\hline \multicolumn{5}{|c|}{$\begin{array}{l}\text { Father's } \\
\text { educational } \\
\text { level }\end{array}$} \\
\hline Primary & 25 & $12(48)$ & & \\
\hline Secondary & 34 & $32(94.1)$ & & \\
\hline Tertiary & 21 & $21(100)$ & 26.6840 & 0.0000 \\
\hline Total & 80 & $65(81.3)$ & & \\
\hline
\end{tabular}




\section{DISCUSSION}

Out of the 80 children whose blood samples were collected, 65 children (81.3\%) had antibodies to all the three polio serotypes. While 75 children $(93.8 \%)$ had antibodies to serotype 1,71 children $(88.8 \%)$ had antibodies to serotype 2 and 74 children (92.5\%) had antibodies to serotype 3 poliovirus. This finding was higher than what Oderinde et al., (2012) found in North Eastern part of the country. The high prevalence can be attributed to increasing number of campaigns carried out by the Agency responsible for immunizing children. The introduction of monovalent oral polio vaccine against type1 polio virus (mOPV1) and type3 (mOPV3), and subsequent replacement of these monovalents with bivalent (bOPV1\&3) might have greatly improve antibodies to polio virus serotypes $1 \& 3$ (Nasr et al., 2008; Zainab et al., 2012).

No significant association between sex, number of doses taken, and place of living was observed. However, other researchers had reported differently (Mehra and Bensal, 1990, Ohri et al., 1999; Oderinde et al., 2012). Age and educational level of the father were found to have a significant effect on the prevalence of antibody in the children sampled, which is in agreement with earlier works done elsewhere (Chaturvedi et al., 1978; Oladejo et al., 2013). This goes to show that refusal which was common in most communities is gradually waning away and the higher the educational level the more the acceptance.

The tremendous improvement in terms of outreaches and supportive supervision over the years might have contributed in bridging the gap in urban and rural areas, thereby enabling the children to be reached in both urban and rural communities as John (2015) observed. Number of doses taken were found not have any statistically significant noticeable effect on the antibody prevalence. A lot of factors might be responsible for this. The major being the inability of mothers to recall the number of doses their children had received (Thomas and Nicholas, 2012).

\section{REFERENCES}

Aliya, N., Shah, S.S.A., Jaffery, S.I.A., Ahmed, S.A., Khan, M.A.B. and Aslam, M. (2015). Seroprevalence rate of Poliovirus antibodies among the Healthy and Protein Energy Malnutrition children. Pakistan Journal of Medical Science; 31(2):403-407.

Atkinson, W.; Hamborsky, J.; McIntyre, L.; Wolfe, S. (2007). "Poliomyelitis" (PDF). Epidemiology and Prevention of Vaccine-Preventable Diseases. (The Pink Book) (10th Ed.). Washington DC: Public Health Foundation. pp. 101-14.

Bodian, D., and D. M. Horstmann. (1965). Polioviruses, p. 430-473. In F. L. Horsfall and I. Tamm (ed.), Viral and rickettsial infections of Man, 4th ed. J. B. Lippincott Co., Philadelphia.

Chaturvedi, U. C. , A. Mathur, U. K. Singh, M. R. Kushwaha, R. M. Mehrotra, A. K. Kapoor, S. Rai, and R. G. Gurha (1978). The problem of
Father's educational level had significant effect in determining who will be at risk in coming down with diseases, which can conveniently be extended to antibody prevalence in any population. It was found out that as the educational level raises so does the prevalence of antibody amongst children. Level of education might have helped in understanding what the vaccine was all about. Thereby allowing children to be vaccinated by house-to-house vaccination teams during campaigns, and allowing mothers to take their children for routine immunization services (Sebahat and Nadi, 2006).

This study has shown that Nigeria need to work harder in order to access and immunize all eligible children for the country to sustain the gain made. The Agency responsible for immunization could use this data to improve immunity level particularly in areas where polio outbreaks might occur.

\section{Conclusion and Recommendation:}

Poliovirus antibody prevalence in the children studied was found to be high in the state. Though considerable progress has been made in comparison to other states in the Northern part of the country (Wood and Thorley, 2003) more work needs to be done in the state so as to ensure all children are reached and eradication finally achieved. Intermittent checking of children's blood samples who are vaccine recipient for serum neutralizing antibody against all the poliovirus serotypes for possible repeat of vaccination will serve as an interventional marker in reducing the burden of poliomyelitis infection.

\section{Acknowledgement}

We want to thank and acknowledge Musa Haruna and Bitrus Shamaki who contributed in running the samples in the laboratory. We want to especially thank the mothers for allowing their children to be enrolled in this study and the state ethical committee for allowing the study to be conducted.

paralytic poliomyelitis in the urban and rural population around Lucknow, India. Journal of Hygiene (Lond).; 81(2): 179-187

Dashe, N. Banwat EB, Dimas D, Agabi YA, Enenebeaku M. (2010). Polio-Specific Immunoglobulin G Antibodies among Children in Jos, Nigeria. Shiraz E Medical Journal, Vol. 11, No. 4.

Guevarra, J.P., Cordova, R.Q. Jr, Mercado, C.E. and Asaad, A.S. (2014). Tobacco use among fourth year Bachelor of Science in Public Health (BSPH) students of the College of Public Health: University of the Philippines Manila, academic year 2012-2013. Journal of Community Health. 39(5):886-893.

John, A.G. (2015). Immunization Manual for Medical and Nursing Students. https://www.scribd.com/doc/288351060/Immu nization Manual for Medical and Nursing Students. \#scribd downloaded 27/11/2015. 
Kew, O., Sutter, R.; de Gourville, E.; Dowdle, W. Pallansch, M. (2005). "Vaccine-derived polioviruses and the endgame strategy for global polio eradication". Annual Review of Microbiology. 59: 587-635.

Mary, A., Laura, P.S., and Shelia, S. (2010). Serologic testing to verify the immune status of internationally adopted children against vaccine preventable diseases. Vaccine $28(50)$; 4947-4955.

Mehra, M, Bansal Y. (1990). Prevalence of paralytic poliomyelitis in a rural and urban community of Delhi. Indian Pediatr, 27(9):915-917.

Nasr, E., Yehia, E., Ahmed, A., Iman, S., Maha, S., Amr, K., Elham, H., Ahmed, S., Heba, A., Mark, A. P., Harrie, G.A.M., Anthony, H.B., Meghana, S., Pradeep, M., Mohamed, H.W. and Roland, W.S. (2008). Monovalent Type 1 Oral Poliovirus Vaccine in Newborns. New England Journal of Medicine 359:1655-166

Oderinde, B.S., Baba M.M., Mohammed U.A., Ojeamiren I., Akinola M.T., Bamaiyi M.J., Ladan J. (2012). A preliminary Study on Neutralizing Antibody to Poliovirus in Adults in Maiduguri, Nigeria Australian Journal of Basic and Applied Sciences, 6(8): 23-27

Ohri, Linda, K.; Jonathan, G. Marquess. (1999). "Polio: Will We Soon Vanquish an Old Enemy? Drug Benefit Trends. 11 (6): 41-54.

Oladejo, O. P. G., O. Nwobu, O. P. Omosigho, M. Baba, S. Oderinde, E. G. Emumwen, K. A. Otojareri, J. Ndako, S.O.Ogedengbe, and A. O. Onoja. (2013). Neutralization Antibodies in Oral Poliovirus Vaccine (OPV) Vaccinated Children and Young Adult in Bida North Central, Nigeria. International Journal of Epidemiology \& Infection.1(2): 19-24
Sebahat, D. T. and Nadi, B. (2006). Vaccination coverage and reasons for non-vaccination in a district of Istanbul. BMC Public Health.; 6: 125

Thomas, R. H. and Nicholas, C.G. (2012). Systematic Review of Mucosal Immunity Induced by Oral and Inactivated Poliovirus Vaccines against Virus Shedding following Oral Poliovirus Challenge. PLoS Pathog. 8(4): e1002599.

Usman, L.G. (2013). An Analysis of Temporal Rainfall Variability in Argungu Area over the Last Half Climatic Year (1995-2012): Implication on Rainfed Crop Production. Academic Journal of Interdisciplinary Studies,2(12): p 117

Wilks, R.; Younger, N.; Mullings, J.; Zohoori, N.; Figueroa, P.; Tulloch-Reid, M.; Ferguson, T.; Walters, C.; Bennett, F.; Forrester, T.; Ward, E. and Ashley, D. (2007). Factors affecting study efficiency and item non-response in health surveys in developing countries: the Jamaica national healthy lifestyle survey. BioMed Central Medical Research Methodology 7 (13).

Wood, N. and B. Thorley (2003). Towards global poliomyelitis eradication: The successes and challenges for a developed country. Journal of Paediatrics and Child Health;39(9): 647-650

Zainab, W., Hennie, G., Roland, W.S., Mariana, J., Humphrey, M., Hassan, M., Marwou, D., Willem, H., Mark, A. P., Anna, L., Anthony, H.B., Meghana, S. and Gregory, H. (2012). Randomized Trial of Type 1 and Type 3 Oral Monovalent Poliovirus Vaccines in Newborns in Africa. The Journal of Infectious Diseases.205(2) Pp. 228-236. 